\title{
Elastography of the Pancreas, Current View
}

\author{
Christoph F. Dietrich ${ }^{1,2}$ and Michael Hocke ${ }^{3}$ \\ ${ }^{1}$ Ultrasound Center, The First Affiliated Hospital of Zhengzhou University, Zhengzhou, China, ${ }^{2}$ Department of Internal Medicine, Caritas \\ Hospital Bad Mergentheim, Bad Mergentheim, Germany, ${ }^{3}$ Department of Internal Medicine, HELIOS Klinikum Meiningen, Meiningen, \\ Germany
}

Ultrasound elastography (USE) of the pancreas allows pancreatic tissue stiffness assessment by virtual palpation. Two main types of USE are used. For the pancreas strain elastography applying by endoscopic ultrasound has been established for the characterisation of small solid pancreatic lesions (SPL). In larger SPL $>30 \mathrm{~mm}$ the results are less convincing mainly due to the heterogenicity of the lesions but also by concomitant changes of the surrounding pancreatic parenchyma. The current role of shear wave elastography has to be determined. This article reviews the current use of elastography of the pancreas. Clin Endosc 2019;52:533-540

Key Words: Endoscopic ultrasound; Neuroendocrine tumour; Shear wave elastography; Ultrasound

\section{INTRODUCTION}

Ultrasound elastography (USE) of the pancreas allows pancreatic tissue stiffness assessment by palpation. Prerequisite of all kinds of elastography is the entire visualization of the gland. ${ }^{1-3}$ Two main types of USE are used: Ultrasound strain elastography (SE) using the endoscopic and transcutaneous route and ultrasound shear wave elastography (SWE) only using the transcutaneous route. ${ }^{4-6}$ The types of USE vary on how the stress is applied and tissue displacement (strain) is measured. SE can be performed with qualitative and semiquantitative information and SWE with qualitative and quantitative data. The description of the basic principles and the terminology has been generally accepted. ${ }^{4,5} \mathrm{SE}$ allows the semi-quantitative evaluation of the strain-ratio (SR) between two regions of interest and the strain-histograms $(\mathrm{SH})$ of a

Received: August 29, 2018 Revised: January 21, 2019

Accepted: January 22, 2019

Correspondence: Christoph F. Dietrich

Department of Internal Medicine, Caritas Hospital Bad Mergentheim, Uhlandstraße 7, Bad Mergentheim 97980, Germany

Tel: +49-7931-58-2201, Fax: +49-7931-58-2290, E-mail: Christoph.dietrich@ ckbm.de

ORCID: https://orcid.org/0000-0001-6015-6347

(c) This is an Open Access article distributed under the terms of the Creative Commons Attribution Non-Commercial License (http://creativecommons.org/ licenses/by-nc/3.0) which permits unrestricted non-commercial use, distribution, and reproduction in any medium, provided the original work is properly cited. certain pancreatic region of interest. ${ }^{7-10}$ Computer-aided diagnostic techniques using artificial neural networks might additionally improve the accuracy for the differential diagnosis of focal pancreatic masses. ${ }^{8,11}$ The advantages of SWE are used for assessment of liver fibrosis, ${ }^{4,5,12-17}$ but only few studies used this technique for the pancreas.

Recommendations have been published for the endoscopic and the transcutaneous approach of strain imaging on how to improve performance. ${ }^{18,19} \mathrm{SE}$ applied by endoscopic ultrasound (EUS) has been established for the characterisation of small solid pancreatic lesions (SPL). In larger SPL $>30 \mathrm{~mm}$, the results are less convincing mainly due to desmoplastic reaction and the heterogenicity of larger lesions with regressive changes but also by concomitant changes of the surrounding pancreatic parenchyma. The current role of the transcutaneously applied SWE is less clear today compared to endoscopically applied strain imaging and has to be determined. This article reviews the current use of elastography of the pancreas.

\section{HOW TO USE STRAIN IMAGING OF THE PANCREAS?}

Ultrasound SE is a qualitative technique where a comparison is performed and relative stiffness differences of the pancreatic tissue are displayed by colours. ${ }^{8,9,12,18-23}$ The trans- 
cutaneous examination technique has been described for the examination of lymph nodes ${ }^{24-29}$ with similiar elastographic features compared to the endoscopic USE approach to examine peripancreatic and other lymphadenopathy. ${ }^{25,30-33}$

We prefer to denote blue as stiffer and red as softer but there are no convincing reasons for this except the historical use. The technical principles of real-time tissue elastography have been recently described in detail by the European Federation of Societies for Ultrasound in Medicine and Biology and the World Federation for Ultrasound in Medicine and Biology. $4,5,12,13,1,1,17,34,36$

Important parameters of SE to take into consideration are listed in the following check list.

- appropriate transducer

- frequency selection

- frame rate

- line density

- palpation speed and amplitude

- noise filters

- persistence

- dynamic range of elasticity

- other qaulity parameters (e.g., strain graph display)

Since strain imaging displays the relative stiffness of tissue, the relation to enough sufficient normal or reference tissue surrounding the lesion is of major interest. The best image quality can be achieved when the lesion of interest covers up to $50 \%$ of the region of interest. ${ }^{18,19,37}$ Too strong pre-compression should be avoided to achieve consistent, reproducible elastograms. The contact of the endoscopic transducer should be strictly applied to the center of the lesion to avoid falsely too stiff estimation. Care should be taken to avoid assessment of tissue adjacent to stiff areas, as soft tissue will strain more when it is above hard tissue. ${ }^{19}$

EUS strain imaging allows the imaging of elasticity properties of SPL but is not suitable for examining larger pure cystic lesions. The blue/green/red sign is a useful artefact to determine the cystic nature of small pancreatic cystic lesion. ${ }^{38}$

\section{NORMAL STIFFNESS OF THE PANCREAS}

The entire pancreas has an intermediate stiffness and the shear wave speed is about $1.4 \mathrm{~m} / \mathrm{sec}^{39}$ Pancreatic stiffness increases during aging which is true for $\mathrm{SE}^{40,41}$ and SWE. .2-44 $^{4}$ Size, body weight, body mass index and gender do not significantly influence pancreatic stiffness ${ }^{42-46}$ but published data are sparse.

\section{ACUTE AND CHRONIC PANCREATITIS, AUTOIMMUNE PANCREATITIS}

Necroses in acute pancreatitis are softer as compared to the healthy pancreatic parenchyma. Acute pancreatitis induces complex changes of the pancreas with no clear cut stiffness values. ${ }^{46-49}$ The value of elastography for the diagnosis of chronic pancreatitis is controversially discussed ${ }^{40,44,46,48,50-68}$ with stiffer parenchyma during the course of the disease both using SE (SR and SH) ${ }^{40,69}$ and SWE. ${ }^{44,46,56,57,70}$ Typically a heterogeneous (honeycombed) stiffness pattern can be displayed with predominantly stiff strands and calcifications. EUS elastography is especially helpful in identifying patients with autoimmune pancreatitis since the entire organ shows stiffer tissue (and hypervascularity) before B-mode changes are visible (Fig. 1). ${ }^{20,71-74}$

Tuberculosis is also stiffer. ${ }^{75,76}$ Elastogaphic methods have also been used to estimate the risk of fistula formation after pancreatic surgery. Interestingly, the softer values are risk factors analysed by $\mathrm{SWE}^{50,51,67,77}$ and $\mathrm{SE}^{54,59,68}$

\section{STRAIN IMAGING}

Recently a study was performed with 218 patients with SPL $\leq 15 \mathrm{~mm}$ and a definite diagnosis. ${ }^{23}$ It could be shown that in patients with small pancreatic lesions, EUS elastography can rule out malignancy with a high level of certainty if the lesion is displayed as soft (Fig. 2).

A stiff lesion can be either benign or malignant. ${ }^{78}$ The most important differential diagnosis of pancreatic ductal adenocarcinoma (PDAC) (Fig. 3) are pancreatic neuroendocrine tumors (Fig. 2).

Other SPL include metastases (e.g., renal cell, lung and colorectal carcinoma) (Fig. 4), lymphoma, serous microcystic neoplasia with only microscopically detectable cysts mimicking a solid lesion, mesenchymal pancreatic tumors and and intrapancreatic accessory spleens. These may present as stiffer or softer lesions compared to the surrounding pancreatic parenchyma. ${ }^{38-42}$

In patients with SPL lesions $<15 \mathrm{~mm}$, it is more likely to diagnose lesions other than ductal adenocarcinoma compared to larger SPL. In multivariate analysis a lesion size of $\geq 15 \mathrm{~mm}$ was associated with PDAC with an Odds ratio of 20.2. ${ }^{79}$ In small pancreatic tumors ( $\leq 25 \mathrm{~mm}$ ), the risk of ductal adenocarcinoma was correlated to increasing size with a risk of ductal adenocarcinoma of $4.3 \%$ in lesions $\leq 15 \mathrm{~mm}$, of $22.8 \%$ of lesions measuring $16-20 \mathrm{~mm}$, and of $42.1 \%$ of leasions measuring $21-25 \mathrm{~mm} .{ }^{80}$ In a large cohort of solid pancreatic tumors (3.4-130 mm; median $32 \mathrm{~mm}$ ) diagnosed using 


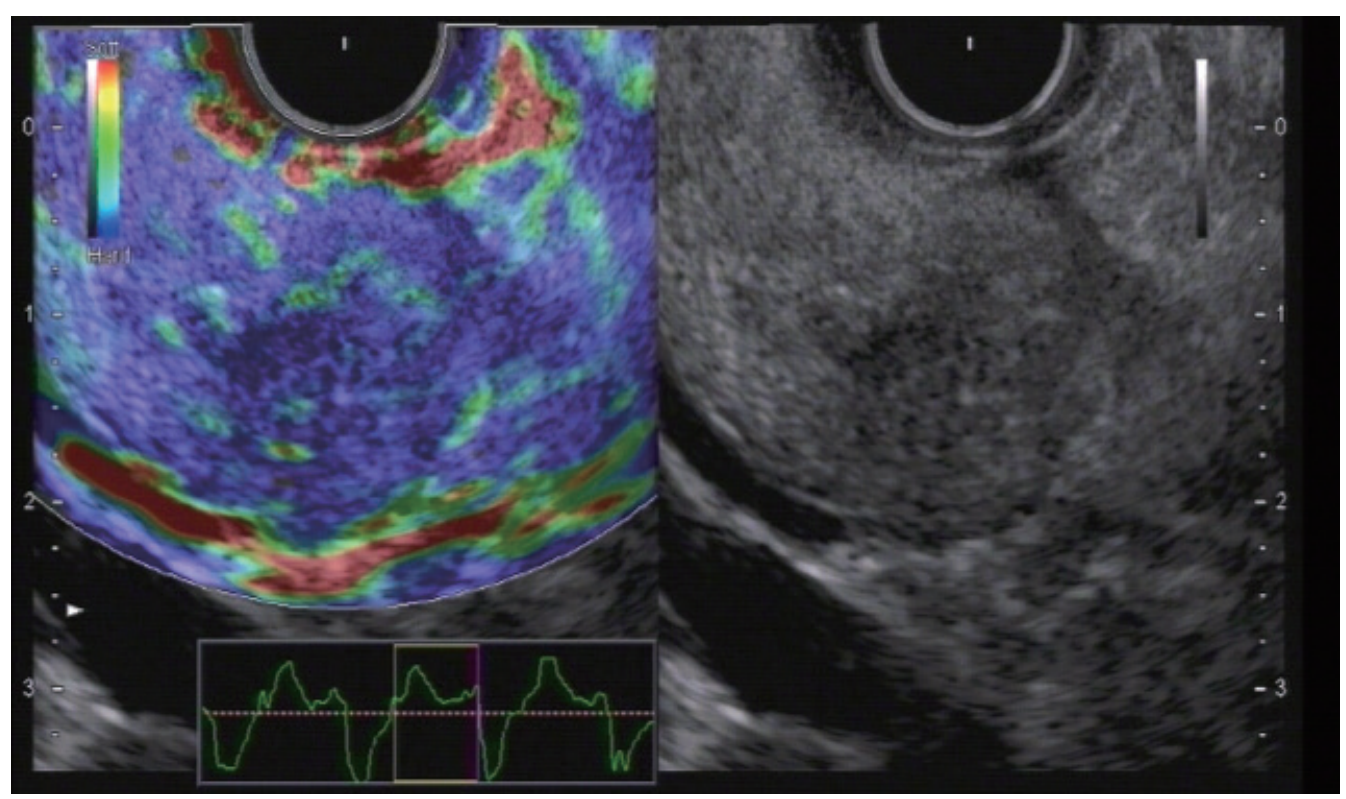

Fig. 1. Autoimmune pancreatitis. The entire organ shows diffuse stiffness. In comparision, pancreatic cancer shows circumscriptive stiffness only.

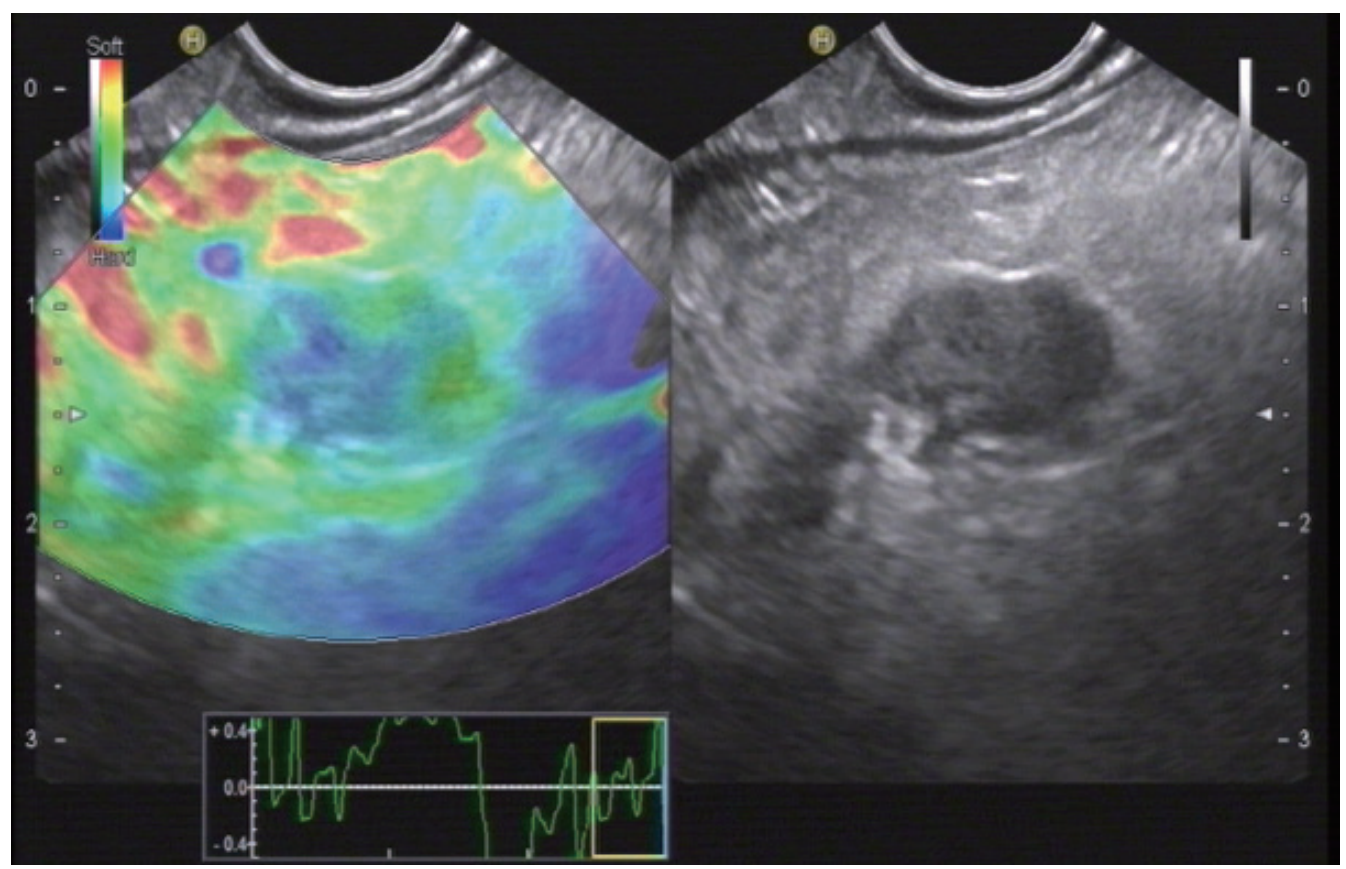

Fig. 2. Neuroendocrine tumour, benign. Endoscopic ultrasound elastography can rule out malignancy with a high level of certainty if the lesion is displayed as soft.

EUS-guided fine needle aspiration (EUS-FNA), 40 lesions were $\leq 10 \mathrm{~mm}$ in diameter, $121 \mathrm{had}$ a diameter of $10-20 \mathrm{~mm}$, and $835>20 \mathrm{~mm}$. In the group of lesions $\leq 10 \mathrm{~mm}$, only $22.5 \%$ were diagnosed to be PDAC, but $40 \%$ proved to be pancreatic neuroendocrine tumours (P-NET). In the group with lesions of intermediate size $(10-20 \mathrm{~mm}) 58.7 \%$ were ductal adenocarcinoma and 14\% were NET. In lesions larger than $20 \mathrm{~mm}$ PDAC was by far the most common diagnosis (81.8\%), and only $2.8 \%$ of lesions were P-NET. ${ }^{81}$ Dawwas et al. reported modest accuracy for differentiating malignant lesions. ${ }^{82}$ They studied 104 patients with evidence of a solid pancreatic mass on cross-sectional imaging and/or endosonography, with 111 quantitative EUS elastography procedures. Multiple elastographic measurements of the mass lesion and soft-tissue reference areas were undertaken, and the corresponding SRs calculated. Malignant masses had a higher SR $(p=0.01)$ and 


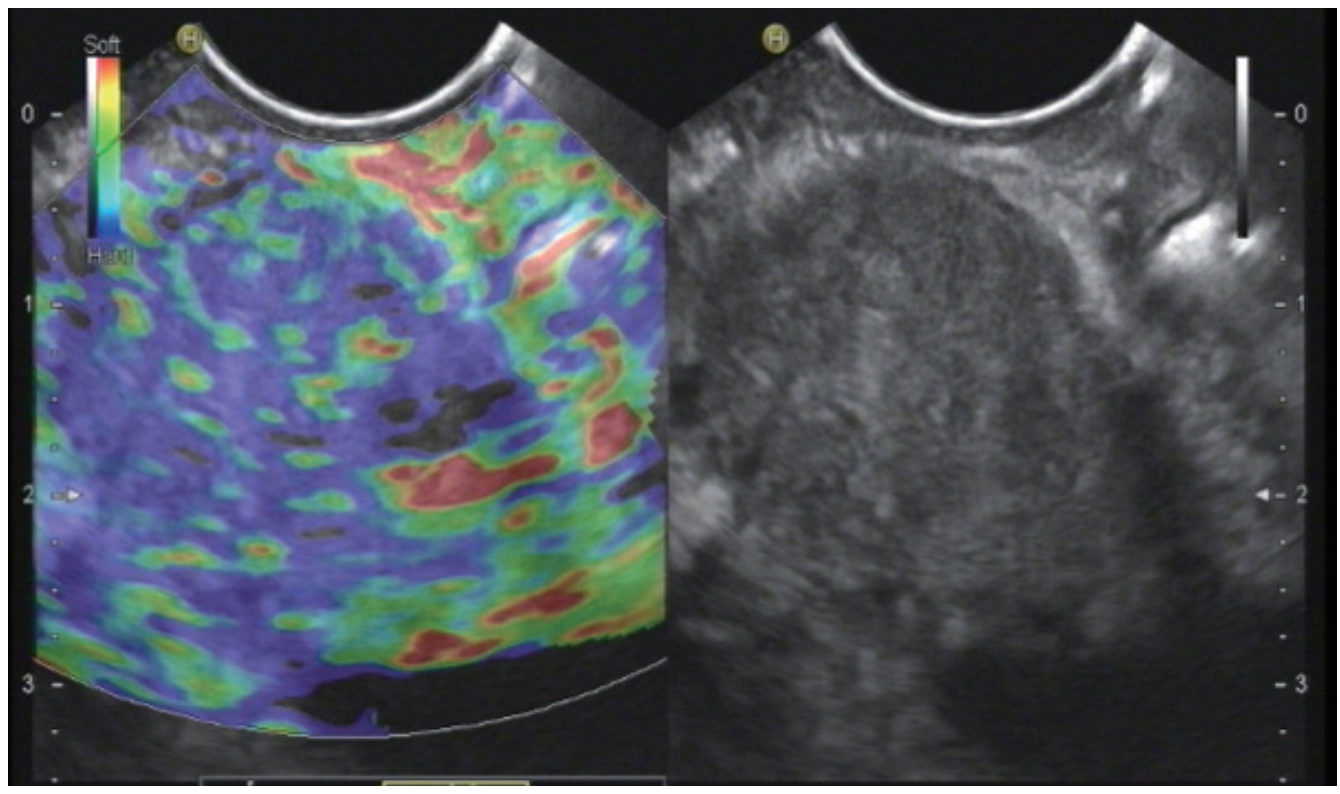

Fig. 3. Pancreatic ductal adenocarcinoma. Elastography show a typical heterogenous stiff pattern.

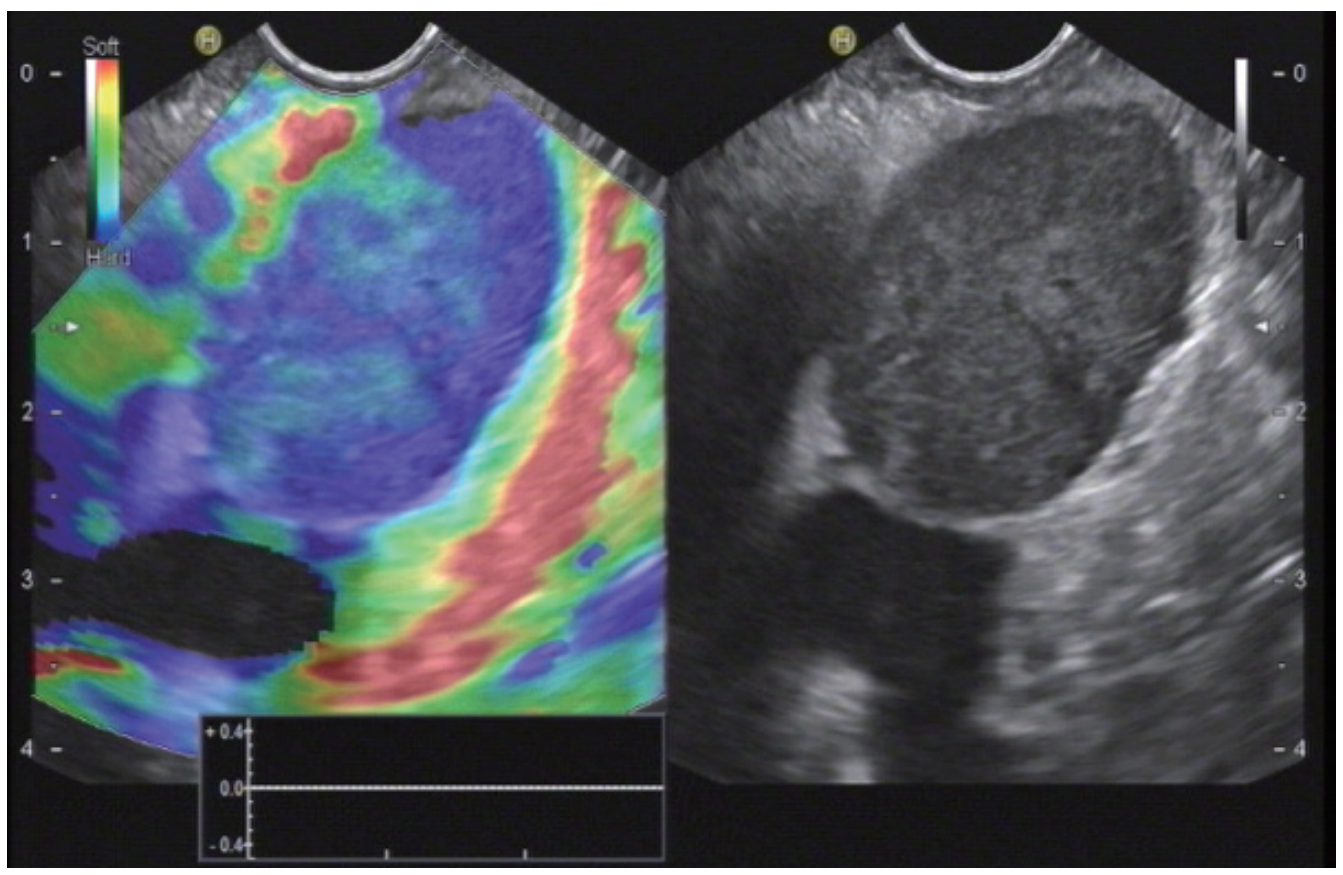

Fig. 4. Pancreatic metastasis of colorectal carcinoma. Elastography show a typical homogenous stiff pattern.

lower mass elasticity $(p=0.003)$ than inflammatory lesions. The areas under the receiver-operating characteristic curve for the detection of pancreatic malignancy of both SR and mass elasticity were 0.69 and 0.72 , respectively. At the cut-off points providing the highest accuracy in this cohort (4.65\% for SR and $0.27 \%$ for mass elasticity), quantitative EUS elastography had a sensitivity of $100.0 \%$ and $95.7 \%$, specificity of $16.7 \%$ and $22.2 \%$, positive predictive value of $86.1 \%$ and $86.4 \%$, negative predictive value of $100.0 \%$ and $50.0 \%$, and overall accuracy of $86.5 \%$ and $83.8 \%$, respectively. The authors suggested that EUS-SE may only supplement rather than supplant the role of pancreatic tissue sampling in the future.

EUS elastography was reported to be useful for the differentiation of focal pancreatic masses, particularly between pseudotumoral chronic pancreatitis and pancreatic cancer, and in the presence of a strong suspicion of pancreatic cancer 
and false-negative EUS-FNA results. ${ }^{83}$ In a retrospective study design, 109 patients with SPL were assessed by EUS elastography. Tissue elasticity distribution and elasticity semiquantification, using the SR of tissue elasticity, were used. Elastography for all PDAC patients showed intense blue coloration, indicating hard tissue. In contrast, mass-forming pancreatitis presented with a mixed coloration pattern of green, yellow, and low-intensity blue. Normal controls showed an even distribution of green to red. The mean SR was $23.66 \pm 12.65$ for mass-forming pancreatitis and $39.08 \pm 20.54$ for PDAC. Semiquantitative analysis of elasticity using the SR may allow the differentiation of mass-forming pancreatitis from PDAC. ${ }^{84}$ Mass forming pancreatitis seems to be a computed tomography phenomenon since it relies mainly on swelling whereas EUS shows most often focal lesions.

One prospective study from 2008 , of 70 patients with undifferentiated pancreatic masses, reported a much lower overall sensitivity of elastography for malignancy of $41 \%$, specificity of $53 \%$, and accuracy of only $45 \%$ in larger lesions. The subanalysis revealed much better results for smaller lesions. ${ }^{21}$

Recent efforts to improve the reproducibility, accuracy, and clinical utility of elastography in pancreatic imaging have moved toward developing quantitative scoring systems for elastography to better delineate the relative differences in the elasticity of solid pancreatic masses. ${ }^{9}$ SR is a tool used for quantifying relative tissue stiffness, normally used to measure the stiffness of a discrete mass lesion. ${ }^{18}$ Histogram analysis has been applied in diffuse chronic pancreatic diseases, where the colour pattern displayed in the elastogram is related to the fibrous structure caused by the chronic inflammatory disease. ${ }^{18}$ Both topics have been extensivle discussed elsewhere. 18,19,23,85 $^{\circ}$

\section{SHEAR WAVE ELASTOGAPHY}

Shear wave velocities are significantly higher in PDAC compared to the surrounding pancreatic parenchyma ${ }^{46,86,87}$ with shear wave velocities $>3 \mathrm{~m} / \mathrm{s}^{46,86-88}$

\section{CONCLUSIONS}

Ultrasound based SE allows improved visualisation and relative quantification of pancreatic tissue stiffness, an area not accessible to direct palpation. $\mathrm{SE}^{5,8-11,19-21,3,1,32,40,41,4,4,52-54,57-63,69,78,84,89-112}$ and $\mathrm{SWE}^{5,39,42-47,50,51,53,55-57,86-90,113-115}$ have been widely used to examine the pancreatic parenchyma and to differentiate SPL. The EUS approach has been established for the differential diagnosis of small SPL. A hypoechoic SPL $<30 \mathrm{~mm}$ on B-mode with low strain signal (hard) in otherwise healthy pancreatic parenchyma can be malignant or benign whereas a soft SPL is almost always benign. The transcutaneous and intraoperative approaches are promising as well but data are less extensive and less convincing. Elastographic methods are not able to decisively differentiate focal pancreatitis from PDAC. Transabdominal and endoscopic USE may be also helpful tools for diagnosing and staging of chronic pancreatitis. Strain imaging is also of use in diagnosing autoimmune pancreatitis. Finally, the combination of imaging methods should be used.

\section{Conflicts of Interest}

The authors have no financial conflicts of interest.

\section{REFERENCES}

1. De Molo C, Cui XW, Pirri C, et al. Pancreas mobile. Z Gastroenterol 2013;51:1165-1170.

2. Pirri C, Cui XW, De Molo C, Ignee A, Schreiber-Dietrich DG, Dietrich CF. The pancreatic head is larger than often assumed. Z Gastroenterol 2013;51:390-394.

3. Sienz M, Ignee A, Dietrich CF. [Reference values in abdominal ultrasound - biliopancreatic system and spleen]. Z Gastroenterol 2011;49:845-870.

4. Bamber J, Cosgrove D, Dietrich CF, et al. EFSUMB guidelines and recommendations on the clinical use of ultrasound elastography. Part 1: basic principles and technology. Ultraschall Med 2013;34:169-184.

5. Shiina T, Nightingale KR, Palmeri ML, et al. WFUMB guidelines and recommendations for clinical use of ultrasound elastography: part 1: basic principles and terminology. Ultrasound Med Biol 2015;41:11261147.

6. Hocke M, Braden B, Jenssen C, Dietrich CF. Present status and perspectives of endosonography 2017 in gastroenterology. Korean J Intern Med 2018;33:36-63.

7. Saftoiu A, Vilman P. Endoscopic ultrasound elastography-- a new imaging technique for the visualization of tissue elasticity distribution. J Gastrointestin Liver Dis 2006;15:161-165.

8. Săftoiu A, Vilmann P, Gorunescu F, et al. Efficacy of an artificial neural network-based approach to endoscopic ultrasound elastography in diagnosis of focal pancreatic masses. Clin Gastroenterol Hepatol 2012;10:84-90.el.

9. Săftoiu A, Vilmann P, Gorunescu F, et al. Accuracy of endoscopic ultrasound elastography used for differential diagnosis of focal pancreatic masses: a multicenter study. Endoscopy 2011;43:596-603.

10. Săftoiu A, Vilmann P. Differential diagnosis of focal pancreatic masses by semiquantitative EUS elastography: between strain ratios and strain histograms. Gastrointest Endosc 2013;78:188-189.

11. Săftoiu A, Vilmann P, Gorunescu F, et al. Neural network analysis of dynamic sequences of EUS elastography used for the differential diagnosis of chronic pancreatitis and pancreatic cancer. Gastrointest Endosc 2008;68:1086-1094.

12. Cosgrove D, Piscaglia F, Bamber J, et al. EFSUMB guidelines and recommendations on the clinical use of ultrasound elastography. Part 2: clinical applications. Ultraschall Med 2013;34:238-253.

13. Ferraioli G, Filice C, Castera L, et al. WFUMB guidelines and recommendations for clinical use of ultrasound elastography: part 3: liver. Ultrasound Med Biol 2015;41:1161-1179.

14. Dong Y, Sirli R, Ferraioli G, et al. Shear wave elastography of the liver review on normal values. Z Gastroenterol 2017;55:153-166.

15. Berzigotti A, Ferraioli G, Bota S, Gilja OH, Dietrich CF. Novel ultra- 
sound-based methods to assess liver disease: the game has just begun. Dig Liver Dis 2018;50:107-112.

16. Dietrich CF, Bamber J, Berzigotti A, et al. EFSUMB guidelines and recommendations on the clinical use of liver ultrasound elastography, update 2017 (short version). Ultraschall Med 2017;38:377-394.

17. Dietrich CF, Bamber J, Berzigotti A, et al. EFSUMB guidelines and recommendations on the clinical use of liver ultrasound elastography, update 2017 (long version). Ultraschall Med 2017;38:e16-e47.

18. Ferraioli G, Wong VW, Castera L, Liver ultrasound elastography: an update to the world federation for ultrasound in medicine and biology guidelines and recommendations. Ultrasound Med Biol 2018;44:24192440.

19. Dietrich CF, Barr RG, Farrokh A, et al. Strain elastography - how to do it? Ultrasound Int Open 2017;3:E137-E149.

20. Dietrich CF, Hirche TO, Ott M, Ignee A. Real-time tissue elastography in the diagnosis of autoimmune pancreatitis. Endoscopy 2009;41:718720 .

21. Hirche TO, Ignee A, Barreiros AP, et al. Indications and limitations of endoscopic ultrasound elastography for evaluation of focal pancreatic lesions. Endoscopy 2008;40:910-917.

22. Havre RF, Ødegaard S, Gilja OH, Nesje LB. Characterization of solid focal pancreatic lesions using endoscopic ultrasonography with real-time elastography. Scand J Gastroenterol 2014;49:742-751.

23. Ignee A, Jenssen C, Arcidiacono PG, et al. Endoscopic ultrasound elastography of small solid pancreatic lesions: a multicenter study. Endoscopy 2018;50:1071-1079.

24. Chiorean L, Barr RG, Braden B, et al. Transcutaneous ultrasound: elastographic lymph node evaluation. Current clinical applications and literature review. Ultrasound Med Biol 2016;42:16-30.

25. Havre RF, Leh SM, Gilja OH, et al. Differentiation of metastatic and non-metastatic mesenteric lymph nodes by strain elastography in surgical specimens. Ultraschall Med 2016;37:366-372.

26. Cui XW, Hocke M, Jenssen C, et al. Conventional ultrasound for lymph node evaluation, update 2013. Z Gastroenterol 2014;52:212-221.

27. Cui XW, Jenssen C, Saftoiu A, Ignee A, Dietrich CF. New ultrasound techniques for lymph node evaluation. World J Gastroenterol 2013;19:4850-4860.

28. Dietrich CF, Hocke M, Jenssen C. [Ultrasound for abdominal lymphadenopathy]. Dtsch Med Wochenschr 2013;138:1001-1018.

29. Dietrich CF, Ponnudurai R, Bachmann Nielsen M. [Is there a need for new imaging methods for lymph node evaluation?]. Ultraschall Med 2012;33:411-414.

30. Dietrich CF, Bojunga J. [Ultrasound of the thyroid]. Z Gastroenterol 2015;53:208-225.

31. Cui XW, Chang JM, Kan QC, Chiorean L, Ignee A, Dietrich CF. Endoscopic ultrasound elastography: current status and future perspectives. World J Gastroenterol 2015;21:13212-13224.

32. Dietrich CF, Săftoiu A, Jenssen C. Real time elastography endoscopic ultrasound (RTE-EUS), a comprehensive review. Eur J Radiol 2014;83:405-414.

33. Janssen J, Dietrich CF, Will U, Greiner L. Endosonographic elastography in the diagnosis of mediastinal lymph nodes. Endoscopy 2007;39:952-957.

34. Barr RG, Nakashima K, Amy D, et al. WFUMB guidelines and recommendations for clinical use of ultrasound elastography: part 2: breast. Ultrasound Med Biol 2015;41:1148-1160.

35. Cosgrove D, Barr R, Bojunga J, et al. WFUMB guidelines and recommendations on the clinical use of ultrasound elastography: part 4 . Thyroid. Ultrasound Med Biol 2017;43:4-26.

36. Barr RG, Cosgrove D, Brock M, et al. WFUMB guidelines and recommendations on the clinical use of ultrasound elastography: part 5 . Prostate. Ultrasound Med Biol 2017;43:27-48.

37. Havre RF, Elde E, Gilja OH, et al. Freehand real-time elastography: impact of scanning parameters on image quality and in vitro intra- and interobserver validations. Ultrasound Med Biol 2008;34:1638-1650.
38. Cho N, Moon WK, Chang JM, Kim SJ, Lyou CY, Choi HY. Aliasing artifact depicted on ultrasound (US)-elastography for breast cystic lesions mimicking solid masses. Acta Radiol 2011;52:3-7.

39. Gallotti A, D’Onofrio M, Pozzi Mucelli R. Acoustic radiation force impulse (ARFI) technique in ultrasound with virtual touch tissue quantification of the upper abdomen. Radiol Med 2010;115:889-897.

40. Janssen J, Papavassiliou I. Effect of aging and diffuse chronic pancreatitis on pancreas elasticity evaluated using semiquantitative EUS elastography. Ultraschall Med 2014;35:253-258.

41. Chantarojanasiri T, Hirooka Y, Kawashima H, et al. Age-related changes in pancreatic elasticity: when should we be concerned about their effect on strain elastography? Ultrasonics 2016;69:90-96.

42. Kawada N, Tanaka S, Uehara H, et al. Potential use of point shear wave elastography for the pancreas: a single center prospective study. Eur J Radiol 2014;83:620-624.

43. Stumpf S, Jaeger H, Graeter T, et al. Influence of age, sex, body mass index, alcohol, and smoking on shear wave velocity (p-SWE) of the pancreas. Abdom Radiol (NY) 2016;41:1310-1316.

44. Yashima $\mathrm{Y}$, Sasahira N, Isayama $\mathrm{H}$, et al. Acoustic radiation force impulse elastography for noninvasive assessment of chronic pancreatitis. J Gastroenterol 2012;47:427-432.

45. Arda K, Ciledag N, Aktas E, Aribas BK, Köse K. Quantitative assessment of normal soft-tissue elasticity using shear-wave ultrasound elastography. AJR Am J Roentgenol 2011;197:532-536.

46. Goertz RS, Schuderer J, Strobel D, Pfeifer L, Neurath MF, Wildner D. Acoustic radiation force impulse shear wave elastography (ARFI) of acute and chronic pancreatitis and pancreatic tumor. Eur J Radiol 2016;85:2211-2216.

47. Xie J, Zou L, Yao M, et al. A preliminary investigation of normal pancreas and acute pancreatitis elasticity using virtual touch tissue quantification (VTQ) imaging. Med Sci Monit 2015;21:1693-1699.

48. Mateen MA, Muheet KA, Mohan RJ, et al. Evaluation of ultrasound based acoustic radiation force impulse (ARFI) and eSie touch sonoelastography for diagnosis of inflammatory pancreatic diseases. JOP 2012;13:36-44.

49. Göya C, Hamidi C, Hattapoğlu S, et al. Use of acoustic radiation force impulse elastography to diagnose acute pancreatitis at hospital admission: comparison with sonography and computed tomography. J Ultrasound Med 2014;33:1453-1460.

50. D’Onofrio M, Tremolada G, De Robertis R, et al. Prevent pancreatic fistula after pancreatoduodenectomy: possible role of ultrasound elastography. Dig Surg 2018;35:164-170.

51. Harada N, Ishizawa T, Inoue $\mathrm{Y}$, et al. Acoustic radiation force impulse imaging of the pancreas for estimation of pathologic fibrosis and risk of postoperative pancreatic fistula. J Am Coll Surg 2014;219:887-894. e5.

52. Kuwahara T, Hirooka Y, Kawashima H, et al. Quantitative diagnosis of chronic pancreatitis using EUS elastography. J Gastroenterol 2017;52:868-874.

53. Kuwahara T, Hirooka Y, Kawashima H, et al. Quantitative evaluation of pancreatic tumor fibrosis using shear wave elastography. Pancreatology 2016;16:1063-1068.

54. Kuwahara T, Hirooka Y, Kawashima H, et al. Usefulness of endoscopic ultrasonography-elastography as a predictive tool for the occurrence of pancreatic fistula after pancreatoduodenectomy. J Hepatobiliary Pancreat Sci 2017;24:649-656.

55. Kuwahara T, Hirooka Y, Kawashima H, et al. Usefulness of shear wave elastography as a quantitative diagnosis of chronic pancreatitis. J Gastroenterol Hepatol 2018;33:756-761.

56. Pozzi R, Parzanese I, Baccarin A, et al. Point shear-wave elastography in chronic pancreatitis: a promising tool for staging disease severity. Pancreatology 2017;17:905-910.

57. Llamoza-Torres CJ, Fuentes-Pardo M, Álvarez-Higueras FJ, Alberca-de-Las-Parras F, Carballo-Álvarez F. Usefulness of percutaneous elastography by acoustic radiation force impulse for the non-invasive 
diagnosis of chronic pancreatitis. Rev Esp Enferm Dig 2016;108:450456.

58. Dominguez-Muñoz JE, Iglesias-Garcia J, Castiñeira Alvariño M, Luaces Regueira M, Lariño-Noia J. EUS elastography to predict pancreatic exocrine insufficiency in patients with chronic pancreatitis. Gastrointest Endosc 2015;81:136-142.

59. Harada N, Yoshizumi T, Maeda T, et al. Preoperative pancreatic stiffness by real-time tissue elastography to predict pancreatic fistula after pancreaticoduodenectomy. Anticancer Res 2017;37:1909-1915.

60. Iglesias-Garcia J, Larino-Noia J, Abdulkader I, Forteza J, Dominguez-Munoz JE. Quantitative endoscopic ultrasound elastography: an accurate method for the differentiation of solid pancreatic masses. Gastroenterology 2010;139:1172-1180.

61. Rana SS, Dambalkar A, Chhabra P, et al. Is pancreatic exocrine insufficiency in celiac disease related to structural alterations in pancreatic parenchyma? Ann Gastroenterol 2016;29:363-366.

62. Janssen J, Schlörer E, Greiner L. EUS elastography of the pancreas: feasibility and pattern description of the normal pancreas, chronic pancreatitis, and focal pancreatic lesions. Gastrointest Endosc 2007;65:971978.

63. Itoh Y, Itoh A, Kawashima H, et al. Quantitative analysis of diagnosing pancreatic fibrosis using EUS-elastography (comparison with surgical specimens). J Gastroenterol 2014;49:1183-1192.

64. Domínguez-Muñoz JE. Predicting pancreatic exocrine insufficiency with EUS elastography. Gastroenterol Hepatol (N Y) 2016;12:511-512.

65. Uchida H, Hirooka Y, Itoh A, et al. Feasibility of tissue elastography using transcutaneous ultrasonography for the diagnosis of pancreatic diseases. Pancreas 2009;38:17-22.

66. Friedrich-Rust M, Schlueter N, Smaczny C, et al. Non-invasive measurement of liver and pancreas fibrosis in patients with cystic fibrosis. J Cyst Fibros 2013;12:431-439.

67. Sugimoto M, Takahashi S, Kojima M, et al. What is the nature of pancreatic consistency? Assessment of the elastic modulus of the pancreas and comparison with tactile sensation, histology, and occurrence of postoperative pancreatic fistula after pancreaticoduodenectomy. Surgery 2014;156:1204-1211.

68. Hatano M, Watanabe J, Kushihata F, et al. Quantification of pancreatic stiffness on intraoperative ultrasound elastography and evaluation of its relationship with postoperative pancreatic fistula. Int Surg 2015;100:497-502.

69. Kim SY, Cho JH, Kim YJ, et al. Diagnostic efficacy of quantitative endoscopic ultrasound elastography for differentiating pancreatic disease. J Gastroenterol Hepatol 2017;32:1115-1122.

70. D’Onofrio M, Crosara S, De Robertis R, Canestrini S, Demozzi E, Pozzi Mucelli R. Elastography of the pancreas. Eur J Radiol 2014;83:415-419.

71. Dong Y, D’Onofrio M, Hocke M, et al. Autoimmune pancreatitis: imaging features. Endosc Ultrasound 2018;7:196-203.

72. Dong Y, Potthoff A, Klinger C, Barreiros AP, Pietrawski D, Dietrich CF. Ultrasound findings in autoimmune hepatitis. World J Gastroenterol 2018;24:1583-1590.

73. Hocke M, Ignee A, Dietrich CF. Three-dimensional contrast-enhanced endoscopic ultrasound for the diagnosis of autoimmune pancreatitis. Endoscopy 2011;43 Suppl 2 UCTN:E381-E382.

74. Hocke M, Ignee A, Dietrich CF. Contrast-enhanced endoscopic ultrasound in the diagnosis of autoimmune pancreatitis. Endoscopy 2011;43:163-165.

75. Dong Y, Jürgensen C, Puri R, et al. Ultrasound imaging features of isolated pancreatic tuberculosis. Endosc Ultrasound 2018;7:119-127.

76. Barreiros AP, Braden B, Schieferstein-Knauer C, Ignee A, Dietrich CF. Characteristics of intestinal tuberculosis in ultrasonographic techniques. Scand J Gastroenterol 2008;43:1224-1231.

77. Lee TK, Kang CM, Park MS, et al. Prediction of postoperative pancreatic fistulas after pancreatectomy: assessment with acoustic radiation force impulse elastography. J Ultrasound Med 2014;33:781-786.

78. Hocke M, Ignee A, Dietrich CF. Advanced endosonographic diagnos- tic tools for discrimination of focal chronic pancreatitis and pancreatic carcinoma--elastography, contrast enhanced high mechanical index (CEHMI) and low mechanical index (CELMI) endosonography in direct comparison. Z Gastroenterol 2012;50:199-203.

79. Wang W, Shpaner A, Krishna SG, et al. Use of EUS-FNA in diagnosing pancreatic neoplasm without a definitive mass on CT. Gastrointest Endosc 2013;78:73-80.

80. Krishna NB, Tummala P, Mehan CD, Reddy AV, Hartman JA, Agarwal B. Small and potentially resectable focal pancreatic lesions noted on CT/MRI scans in nonjaundiced patients: likelihood of neoplasia and utility of EUS. J Gastrointest Surg 2012;16:793-800.

81. Haba S, Yamao K, Bhatia V, et al. Diagnostic ability and factors affecting accuracy of endoscopic ultrasound-guided fine needle aspiration for pancreatic solid lesions: Japanese large single center experience. J Gastroenterol 2013;48:973-981.

82. Dawwas MF, Taha H, Leeds JS, Nayar MK, Oppong KW. Diagnostic accuracy of quantitative EUS elastography for discriminating malignant from benign solid pancreatic masses: a prospective, single-center study. Gastrointest Endosc 2012;76:953-961.

83. Săftoiu A. State-of-the-art imaging techniques in endoscopic ultrasound. World J Gastroenterol 2011;17:691-696.

84. Itokawa F, Itoi T, Sofuni A, et al. EUS elastography combined with the strain ratio of tissue elasticity for diagnosis of solid pancreatic masses. J Gastroenterol 2011;46:843-853.

85. Hocke M, Topalidis T, Braden B, Dietrich CF. "Clinical” cytology for endoscopists: a practical guide. Endosc Ultrasound 2017;6:83-89.

86. Onoyama T, Koda M, Fujise Y, et al. Utility of virtual touch quantification in the diagnosis of pancreatic ductal adenocarcinoma. Clin Imaging 2017;42:64-67.

87. D’Onofrio M, De Robertis R, Crosara S, et al. Acoustic radiation force impulse with shear wave speed quantification of pancreatic masses: a prospective study. Pancreatology 2016;16:106-109.

88. Park MK, Jo J, Kwon H, et al. Usefulness of acoustic radiation force impulse elastography in the differential diagnosis of benign and malignant solid pancreatic lesions. Ultrasonography 2014;33:26-33.

89. Hirooka Y, Kuwahara T, Irisawa A, et al. JSUM ultrasound elastography practice guidelines: pancreas. J Med Ultrason (2001) 2015;42:151174.

90. Kawada N, Tanaka S. Elastography for the pancreas: current status and future perspective. World J Gastroenterol 2016;22:3712-3724.

91. Chantarojanasiri T, Hirooka Y, Kawashima H, et al. Endoscopic ultrasound in diagnosis of solid pancreatic lesions: elastography or contrast-enhanced harmonic alone versus the combination. Endosc Int Open 2017;5:E1136-E1143.

92. Dyrla P, Gil J, Florek M, et al. Elastography in pancreatic solid tumours diagnoses. Prz Gastroenterol 2015;10:41-46.

93. Iglesias García JJ, Lariño Noia J, Alvarez Castro A, Cigarrán B, Domínguez Muñoz JE. Second-generation endoscopic ultrasound elastography in the differential diagnosis of solid pancreatic masses. Pancreatic cancer vs. inflammatory mass in chronic pancreatitis. Rev Esp Enferm Dig 2009;101:723-730.

94. Iglesias-Garcia J, Domínguez-Muñoz JE, Castiñeira-Alvariño M, Luaces-Regueira M, Lariño-Noia J. Quantitative elastography associated with endoscopic ultrasound for the diagnosis of chronic pancreatitis. Endoscopy 2013;45:781-788

95. Iglesias-Garcia J, Lindkvist B, Lariño-Noia J, Abdulkader-Nallib I, Dominguez-Muñoz JE. Differential diagnosis of solid pancreatic masses: contrast-enhanced harmonic (CEH-EUS), quantitative-elastography (QE-EUS), or both? United European Gastroenterol J 2017;5:236246.

96. Iordache S, Costache MI, Popescu CF, Streba CT, Cazacu S, Săftoiu A. Clinical impact of EUS elastography followed by contrast-enhanced EUS in patients with focal pancreatic masses and negative EUS-guided FNA. Med Ultrason 2016;18:18-24.

97. Kawada N, Tanaka S, Uehara H, et al. Alteration of strain ratio evalu- 
ated by transabdominal ultrasound elastography may predict the efficacy of preoperative chemoradiation performed for pancreatic ductal carcinoma: preliminary results. Hepatogastroenterology 2014;61:480483.

98. Kongkam P, Lakananurak N, Navicharern P, et al. Combination of EUS-FNA and elastography (strain ratio) to exclude malignant solid pancreatic lesions: a prospective single-blinded study. J Gastroenterol Hepatol 2015;30:1683-1689.

99. Opačić D, Rustemović N, Kalauz M, et al. Endoscopic ultrasound elastography strain histograms in the evaluation of patients with pancreatic masses. World J Gastroenterol 2015;21:4014-4019.

100. Rustemović N, Kalauz M, Grubelić Ravić K, et al. Differentiation of pancreatic masses via endoscopic ultrasound strain ratio elastography using adjacent pancreatic tissue as the reference. Pancreas 2017;46:347351.

101. Dietrich CF. [Elastography, the new dimension in ultrasonography]. Praxis (Bern 1994) 2011;100:1533-1542.

102. Dietrich CF, Cantisani V. Current status and perspectives of elastography. Eur J Radiol 2014;83:403-404.

103. Azemoto N, Kumagi T, Koizumi M, et al. Diagnostic challenge in pancreatic sarcoidosis using endoscopic ultrasonography. Intern Med 2018;57:231-235.

104. Chantarojanasiri T, Hirooka Y, Kawashima H, et al. Endoscopic ultrasound in the diagnosis of acinar cell carcinoma of the pancreas: contrast-enhanced endoscopic ultrasound, endoscopic ultrasound elastography, and pathological correlation. Endosc Int Open 2016;4:E1223-E1226.

105. Jafri M, Sachdev AH, Khanna L, Gress FG. The role of real time endoscopic ultrasound guided elastography for targeting EUS-FNA of suspicious pancreatic masses: a review of the literature and a single center experience. JOP 2016;17:516-524.

106. Lee TH, Cho YD, Cha SW, et al. Endoscopic ultrasound elastography for the pancreas in Korea: a preliminary single center study. Clin Endosc 2013;46:172-177.

107. Pei Q, Zou X, Zhang X, Chen M, Guo Y, Luo H. Diagnostic value of EUS elastography in differentiation of benign and malignant solid pancreatic masses: a meta-analysis. Pancreatology 2012;12:402-408

108. Popescu A, Ciocalteu AM, Gheonea DI, et al. Utility of endoscopic ultrasound multimodal examination with fine needle aspiration for the diagnosis of pancreatic insulinoma - a case report. Curr Health Sci J 2012;38:36-40.

109. Rana SS, Sharma R, Guleria S, Gupta R. Endoscopic ultrasound (EUS) elastography and contrast enhanced EUS in groove pancreatitis. Indian J Gastroenterol 2018;37:70-71.

110. Schrader H, Wiese M, Ellrichmann M, et al. Diagnostic value of quantitative EUS elastography for malignant pancreatic tumors: relationship with pancreatic fibrosis. Ultraschall Med 2012;33:E196-E201.

111. Soares JB, Iglesias-Garcia J, Goncalves B, et al. Interobserver agreement of EUS elastography in the evaluation of solid pancreatic lesions. Endosc Ultrasound 2015;4:244-249.

112. Rustemovic N, Opacic D, Ostojic Z, et al. Comparison of elastography methods in patients with pancreatic masses. Endosc Ultrasound 2014;3(Suppl 1):S4.

113. He Y, Wang H, Li XP, Zheng JJ, Jin CX. Pancreatic elastography from acoustic radiation force impulse imaging for evaluation of diabetic microangiopathy. AJR Am J Roentgenol 2017;209:775-780.

114. Sağlam D, Bilgici MC, Kara C, Yilmaz GC, Çamlıdağ I. Acoustic radiation force impulse elastography in determining the effects of type 1 diabetes on pancreas and kidney elasticity in children. AJR Am J Roentgenol 2017;209:1143-1149.

115. Zaro R, Lupsor-Platon M, Cheviet A, Badea R. The pursuit of normal reference values of pancreas stiffness by using acoustic radiation force impulse (ARFI) elastography. Med Ultrason 2016;18:425-430 